\title{
Role of exercise on molecular mechanisms in the regulation of antidepressant effects
}

\author{
Hyo-Jun Lee, Seung-Soo Baek* \\ Department of Sport \& Health Science, College of Natural Science, Sangmyung University, Seoul, Korea
}

Regular exercise reduces depressive-like behavior activation. In this study, we look for exact roles of exercise on molecular and neuronal mechanisms for antidepressant action by studying the hippocampal neuroplasticity and proliferation. Increased hippocampal neurogenesis with exercise has potential significance for depression. Exercise promotes brain health in the molecular levels in the hippocampus and also affects behavior in a similar way to chronic antidepressant treatment. Wingless (Wnt) and frizzled signaling system plays an important role in cell proliferation, growth, and differentiation during development. Our results demonstrate complicated, differential effects of antidepressants on Wnt signaling system, and assume a role for selected signaling molecules in the neurogenic activity of antidepressant care. Our review suggests that exercise may preserve brain function by increasing neurogenesis through activating Wnt signaling pathway in the psychiatric disorders, such as depression.

Keywords: Hippocampal neurogenesis, Antidepressant-like behavior, Neuroplasticity, Depression, Exercise

\section{INTRODUCTION}

Mood disorders such as depression result enormous personal distress. Intrinsic depression has not fully verified, but is deliberated to from molecular and cellular singularities. Available antidepressants have significant limitations. This is a particular problem in diseases that increase suicide rates. Various interventions are known to have antidepressant action, including medication, sleep deprivation, enriched environment and exercise (Lawlor and Hopker, 2001).

Exercise impacts every system in the body. Benefits of regular exercise include increased cardiovascular fitness, improved bone mineral density, decreased risk for cancer, stroke, and diabetes (Cotman and Engesser-Cesar, 2002). Exercise enhances adult hippocampal neurogenesis and also promotes antidepressant-like behaviors. Regular physical exercise stimulates cell proliferation and recruits new neurons in the hippocampal dentate gyrus of the brain. Chronic exercise reduces depressive-like behavior in rats and mice, as measured in standard models of depression such as the forced swim test (Bjørnebekk et al., 2005; Duman et al., 2008). The molecular pathways prevalent in these treatments are not yet known (Huang et al., 2012).

In this study, we look for roles of exercise on molecular and neuronal mechanisms for antidepressant action by studying the hippocampal neuroplasticity and proliferation. The aim of the present study is to review the possibility whether exercise regulates depression-associated antidepressant effects in the brain. Therefore, in this study, the roles of exercise on molecular mechanisms in the regulation of antidepressant effects in relation with hippocampal neurogenesis, were reviewed using antidepressant-like behavior, and signaling pathways of treatment of depression.

\section{EXERCISE-INDUCED HIPPOCAMPAL NEUROGENESIS MEDIATES RECOVERY FROM DEPRESSION}

Increased hippocampal neurogenesis with exercise has potential significance for depression. Exercise is recommended to patients
${ }^{*}$ Corresponding author: Seung-Soo Baek (ib https://orcid.org/0000-0002-1340-2098 Department of Sport \& Health Science, College of Natural Science, Sangmyung University, 20 Hongjimun 2-gil, Jongno-gu, Seoul 03016, Korea Tel: +82-2-2287-5133, Fax: +82-2-2287-0075, E-mail: ssoop@smu.ac.kr Received: November 13, 2017 / Accepted: December 18, 2017
This is an Open Access article distributed under the terms of the Creative Commons Attribution Non-Commercial License (http://creativecommons.org/licenses/by-nc/4.0/) which permits unrestricted non-commercial use, distribution, and reproduction in any medium, provided the original work is properly cited. 
suffering from depression as a means of developing their psychological wellness. Most exercises were found to have positive effects on depression for both clinical and healthy participants (Cotman and Engesser-Cesar, 2002).

Neuronal networks can be selectively strengthened by the recruitment of new neurons formed from hippocampal neurogenesis, including neural stem cells proliferates and differentiate into neurons and glial cells (Cotman and Engesser-Cesar, 2002). Increased new neurons could be founded in the dentate gyrus of hippocampus of animals living in enriched environment where they are exposed to social interaction, learning, and exercise (Huang et al., 2012). Exercise alone is sufficient to improve neurogenesis, including for the possibility of strengthening neuronal connections (Cotman and Engesser-Cesar, 2002).

Brain-derived neurotrophic factor (BDNF) mRNA levels is decreased in the hippocampus by exposure to stress, which can be connected to depression (Russo-Neustadt et al., 2001). Stress-induced hippocampal neurogenesis decrease may also be linked to depression. Both exercise and antidepressants can increase hippocampal neurogenesis in the brain. Thus, exercise alone or antidepressants administrations can lead to significantly greater increase in hippocampal neurogenesis. It is possible that exercise promotes brain health in the molecular levels in the hippocampus.

Some studies evaluated whether voluntary exercise had the expected antidepressant effects by comparing exercising animals to controls in behaviors that were found to be modulated in response to fluoxetine: novelty suppressed feeding, marble burying and digging activity in a new environment, and novelty induced hypophagia (Dulawa and Hen, 2005; Huang et al., 2008; Huang et al., 2012; Njung'e and Handley, 1991). Animals in the exercise group less burying and digging activities in compared to controls, however, exercise group showed a significant increase in the time spent in eating food after overnight deprivation (Huang et al., 2012). Also, the exercise group showed a significant increase in the time spent drinking in a bright cage (Huang et al., 2012). These results represent that exercise affects behavior in a similar way to chronic antidepressant treatment.

\section{NEUROPLASTICITY AND PROLIFERATION}

Classical research in the neurobiology of major depressive disorder had been focused on monoamines. A hypothesis, however, has tried to explain depression based on molecular mechanisms of neuroplasticity (Duman et al., 1997). Stress decrease hippocampal neurogenesis and synaptic plasticity in prefrontal cortex. Most an- tidepressant therapies stimulate the proliferation of hippocampal progenitor cells (Pilar-Cuéllar et al., 2013).

New explanations about the neurobiology of depression and the mechanism of action of antidepressant therapies based on cellular changes at the central nervous system level have been provided. The neurotrophic/plasticity hypothesis of depression is now supported by multiple studies focused on the role of intracellular-signaling cascades that regulate neuroplasticity and neural proliferation (Warner-Schmidt and Duman, 2006). However, the influence of hippocampal neurogenesis to the pathogenesis of depression is not entirely understood. Some studies suggest that decreased neurogenesis in depressed patients reveals hippocampal volumetric reductions (Pilar-Cuéllar et al., 2013). These morphologic changes and gray matter alterations could be due to changes in neuropil, glial number, and dendritic complexity (Sahay et al., 2007). Finally, different neuroplasticity- and proliferation-related intracellular pathways appear to be involved in the antidepressants' action as BDNF, $\beta$-catenin, or the mammalian target of rapamycin (mTOR) (Li et al., 2010)

Adult hippocampal neurogenesis cannot entirely explain major depression (Pilar-Cuéllar et al., 2013). Synaptic plasticity and neural proliferation can also be involved in the neurobiological basis of depression via modulating by antidepressant treatments (Duman et al., 1997). Depression reduces synaptic plasticity in the hippocampus-prefrontal cortex neuronal pathway (Cerqueira et al., 2007). The increase in extracellular glutamate can be one of the reasons underlying the molecular changes associated to stress (Popoli et al., 2011). Thus, changes in synaptic plasticity will reveal a vulnerability to suffer a depression episode. On the other hands, it has been suggested that an increase in serotonin levels via exercise mediates the increase in cell proliferation (Baek et al., 2012). The neuroplastic changes of the brain linked to antidepressant effects promoted by exercise. We should not underestimate the significance of synaptic plasticity via exercise in those antidepressant treatments that are not followed with increased proliferation.

\section{SIGNALING PATHWAYS OF TREATMENT OF DEPRESSION}

Recent studies showed that depression is associated with loss of neurons and glia in the hippocampus (Duman and Voleti, 2012). Here we review findings that suggest a possible role for glycogen synthase kinase 3 (GSK 3) and upstream wingless (Wnt)-frizzled (Fz) signaling pathways in depression. 
GSK 3 is expressed in most areas of the brain. GSK 3 is found in two isoforms, $\alpha$ and $\beta$, both of which are inhibited by phosphorylation (Duman and Voleti, 2012). GSK 3 is phosphorylated and inhibited by selective serotonin reuptake inhibitor (SSRI) antidepressants via activation of 5-HT1A receptors ( $\mathrm{Li}$ and Jope, 2010). One of the primary downstream targets of GSK 3 is $\beta$-catenin. Phosphorylated $\beta$-catenin is targeted for proteasomal degradation (Henderson, 2000). Inhibition of GSK 3 increases $\beta$-catenin availability for cell structural support or regulation of gene transcription (Duman and Voleti, 2012).

On the other hands, GSK 3 controls cAMP response elementbinding, hippocampal neurogenesis and neuroprotection, which have been related in the actions of antidepressant treatments (Henderson, 2000; Li and Jope, 2010). GSK-3 $\beta$ has been associated with behavioral characteristics in depressed patients (Saus et al., 2010). Recent studies showed that GSK 3 antagonists produce antidepressant and antimanic responses in rats (Gould et al., 2004; Rosa et al., 2008). Phosphorylation of GSK 3 could be increased by ketamine, which is a rapid and effective treatment for bipolar depression and suicide ideation in patients with depression (Price et al., 2009).

The Wnt and Fz receptor signaling system is upstream regulator of GSK 3, which has been involved in the actions of antidepressants (Hu et al., 2011). Wnt and Fz signaling system plays an important role in cell proliferation, growth, and differentiation during development. Wnt isoforms and Fz receptor subtypes play roles in the survival, function and plasticity of neurons in the brain (Budnik and Salinas, 2011). Chronic antidepressant treatment, such as SSRIs, dual uptake inhibitors and electroconvulsive seizures, improve Wnt 2 expression in the hippocampus of the brain. Increased expression of Wnt 2 influences an antidepressant response in the learned helplessness (Okamoto et al., 2010). Wnt 3a is improved by SSRI treatment and is connected with hippocampal neurogenesis (Zhou et al., 2016). These results demonstrate complicated, differential effects of antidepressants on Wnt signaling system, and assume a role for selected signaling molecules in the neurogenic activity of antidepressant care.

Exercise decreases the serum levels of Dickkpof- 1 and secreted frizzled-related protein-1 and improves physical fitness and biomarker levels related to metabolic conditions (Kim et al., 2017). These results demonstrate that the possible involvement of Wnt signaling in the beneficial effects of exercise reveals useful diagnostic/prognostic biomarkers and therapeutic targets (Kim et al., 2017). Exercise activated Wnt signaling pathway, which caused inhibition on GSK-3 $\beta$ expression, therefore, GSK- $3 \beta$ negatively affects the proliferation of neural precursors and hippocampal neurogenesis (Kim et al., 2016; Tiwari et al., 2014).

The expression of Wnt was increased by treadmill running exercise (Kim et al., 2016). The present results showed that exercise alleviates depression-like behavior via inhibiting the expression of GSK-3 $\beta$. Our review suggests that exercise may preserve brain function by increasing neurogenesis through activating Wnt signaling pathway in the psychiatric disorders, such as depression.

\section{CONCLUSIONS}

The present study showed evidences suggesting that exerciseinduced enhancement in neuroplasticity and neurogenesis are linked with treatment of depression in the brain. Antidepressant-like effect in exercise is related with neurogenesis, BDNF, $\beta$-catenin, mTOR, and molecular signaling pathways in the hippocampus. Understanding of molecular and cellular mechanisms of exercise on antidepressant effects may lead to the progress of new therapeutic strategy for psychiatric disorders.

\section{CONFLICT OF INTEREST}

No potential conflict of interest relevant to this article was reported.

\section{ACKNOWLEDGMENTS}

This work was supported by the 2016 Research Grant of Sangmyung University.

\section{REFERENCES}

Baek SS, Jun TW, Kim KJ, Shin MS, Kang SY, Kim CJ. Effects of postnatal treadmill exercise on apoptotic neuronal cell death and cell proliferation of maternal-separated rat pups. Brain Dev 2012;34:45-56.

Bjørnebekk A, Mathé AA, Brené S. The antidepressant effect of running is associated with increased hippocampal cell proliferation. Int J Neuropsychopharmacol 2005;8:357-368.

Budnik V, Salinas PC. Wnt signaling during synaptic development and plasticity. Curr Opin Neurobiol 2011;21:151-159.

Cerqueira JJ, Mailliet F, Almeida OF, Jay TM, Sousa N. The prefrontal cortex as a key target of the maladaptive response to stress. J Neurosci 2007;27:2781-2787.

Cotman CW, Engesser-Cesar C. Exercise enhances and protects brain function. Exerc Sport Sci Rev 2002;30:75-79. 
Dulawa SC, Hen R. Recent advances in animal models of chronic antidepressant effects: the novelty-induced hypophagia test. Neurosci Biobehav Rev 2005;29:771-783.

Duman $\mathrm{CH}$, Schlesinger L, Russell DS, Duman RS. Voluntary exercise produces antidepressant and anxiolytic behavioral effects in mice. Brain Res 2008;1199:148-158.

Duman RS, Heninger GR, Nestler EJ. A molecular and cellular theory of depression. Arch Gen Psychiatry 1997;54:597-606.

Duman RS, Voleti B. Signaling pathways underlying the pathophysiology and treatment of depression: novel mechanisms for rapid-acting agents. Trends Neurosci 2012;35:47-56.

Gould TD, Einat H, Bhat R, Manji HK. AR-A014418, a selective GSK-3 inhibitor, produces antidepressant-like effects in the forced swim test. Int J Neuropsychopharmacol 2004;7:387-390.

Henderson BR. Nuclear-cytoplasmic shuttling of APC regulates beta-catenin subcellular localization and turnover. Nat Cell Biol 2000;2:653660.

Hu LW, Kawamoto EM, Brietzke E, Scavone C, Lafer B. The role of Wnt signaling and its interaction with diverse mechanisms of cellular apoptosis in the pathophysiology of bipolar disorder. Prog Neuropsychopharmacol Biol Psychiatry 2011;35:11-17.

Huang GJ, Bannerman D, Flint J. Chronic fluoxetine treatment alters behavior, but not adult hippocampal neurogenesis, in BALB/cJ mice. Mol Psychiatry 2008;13:119-121.

Huang GJ, Ben-David E, Tort Piella A, Edwards A, Flint J, Shifman S. Neurogenomic evidence for a shared mechanism of the antidepressant effects of exercise and chronic fluoxetine in mice. PLoS One 2012;7:e35901.

Kim DY, Jung SY, Kim K, Kim CJ. Treadmill exercise ameliorates Alzheimer disease-associated memory loss through the Wnt signaling pathway in the streptozotocin-induced diabetic rats. J Exerc Rehabil 2016; 12:276-283.

Kim TH, Chang JS, Park KS, Park J, Kim N, Lee JI, Kong ID. Effects of exercise training on circulating levels of Dickkpof-1 and secreted frizzled-related protein-1 in breast cancer survivors: A pilot single-blind randomized controlled trial. PLoS One 2017;12:e0171771.

Lawlor DA, Hopker SW. The effectiveness of exercise as an intervention in the management of depression: systematic review and meta-regression analysis of randomised controlled trials. BMJ 2001;322:763-767.

Li N, Lee B, Liu RJ, Banasr M, Dwyer JM, Iwata M, Li XY, Aghajanian G, Duman RS. mTOR-dependent synapse formation underlies the rapid antidepressant effects of NMDA antagonists. Science 2010;329:959-964.

Li X, Jope RS. Is glycogen synthase kinase-3 a central modulator in mood regulation? Neuropsychopharmacology 2010;35:2143-2154.

Njung'e K, Handley SL. Evaluation of marble-burying behavior as a mod- el of anxiety. Pharmacol Biochem Behav 1991;38:63-67.

Okamoto H, Voleti B, Banasr M, Sarhan M, Duric V, Girgenti MJ, Dileone RJ, Newton SS, Duman RS. Wnt2 expression and signaling is increased by different classes of antidepressant treatments. Biol Psychiatry 2010; 68:521-527.

Pilar-Cuéllar F, Vidal R, Díaz A, Castro E, dos Anjos S, Pascual-Brazo J, Linge R, Vargas V, Blanco H, Martínez-Villayandre B, Pazos Á, Valdizán EM. Neural plasticity and proliferation in the generation of antidepressant effects: hippocampal implication. Neural Plast 2013;2013:537265.

Popoli M, Yan Z, McEwen BS, Sanacora G. The stressed synapse: the impact of stress and glucocorticoids on glutamate transmission. Nat Rev Neurosci 2011;13:22-37.

Price RB, Nock MK, Charney DS, Mathew SJ. Effects of intravenous ketamine on explicit and implicit measures of suicidality in treatment-resistant depression. Biol Psychiatry 2009;66:522-526.

Rosa AO, Kaster MP, Binfaré RW, Morales S, Martín-Aparicio E, Navarro-Rico ML, Martinez A, Medina M, García AG, López MG, Rodrigues AL. Antidepressant-like effect of the novel thiadiazolidinone NP031115 in mice. Prog Neuropsychopharmacol Biol Psychiatry 2008;32:15491556.

Russo-Neustadt A, Ha T, Ramirez R, Kesslak JP. Physical activity-antidepressant treatment combination: impact on brain-derived neurotrophic factor and behavior in an animal model. Behav Brain Res 2001;120: 87-95.

Sahay A, Drew MR, Hen R. Dentate gyrus neurogenesis and depression. Prog Brain Res 2007;163:697-722.

Saus E, Soria V, Escaramís G, Crespo JM, Valero J, Gutiérrez-Zotes A, Martorell L, Vilella E, Menchón JM, Estivill X, Gratacòs M, Urretavizcaya M. A haplotype of glycogen synthase kinase $3 \beta$ is associated with early onset of unipolar major depression. Genes Brain Behav 2010;9:799807.

Tiwari SK, Agarwal S, Seth B, Yadav A, Nair S, Bhatnagar P, Karmakar M, Kumari M, Chauhan LK, Patel DK, Srivastava V, Singh D, Gupta SK, Tripathi A, Chaturvedi RK, Gupta KC. Curcumin-loaded nanoparticles potently induce adult neurogenesis and reverse cognitive deficits in Alzheimer's disease model via canonical Wnt/ $\beta$-catenin pathway. ACS Nano 2014;8:76-103.

Warner-Schmidt JL, Duman RS. Hippocampal neurogenesis: opposing effects of stress and antidepressant treatment. Hippocampus 2006;16: 239-249.

Zhou WJ, Xu N, Kong L, Sun SC, Xu XF, Jia MZ, Wang Y, Chen ZY. The antidepressant roles of Wnt2 and Wnt 3 in stress-induced depression-like behaviors. Transl Psychiatry 2016;6:e892. 